\title{
SIMULASI KENDALI TEKANAN KOMPRESOR PADA ELECTRICALLY ASSISTED TURBOCHARGER DENGAN METODE PI-GAIN SCHEDULING
}

\author{
Miftahuddin Arsyahadij ${ }^{*}$, Iwan Setiawan, dan Yuli Christyono \\ Departemen Teknik Elektro, Universitas Diponegoro \\ J1. Prof. Sudharto, SH, Kampus UNDIP Tembalang, Semarang 50275, Indonesia \\ ${ }^{*}$ E-mail: marsyahadij@gmail.com
}

\begin{abstract}
Abstrak
Mayoritas dari mobil-mobil berpenumpang didesain sehingga memiliki performa yang handal, hemat bahan bakar, dan rendah emisi gas buang. Dalam hal kemampuan sebuah mobil mampu mengatasi berbagai medan jalan yang ada maka performa yang handal menjadi fokus dari pengembangan mobil-mobil saat ini. Beberapa cara untuk meningkatkan performa dari SI engine adalah variasi pemilihan bahan bakar, mengubah rasio kompresi mesin, mengubah nilai air to fuel ratio (AFR), dan menggunakan turbocharger. Turbocharger merupakan salah satu cara yang terbaik. Turbocharger juga memiliki kelemahan apabila diterapkan di SI engine yaitu terjadinya kondisi turbo lag. Penelitian ini merancang sistem kendali yang pada EAT untuk meminimalkan turbo lag pada turbocharger. Metode sistem kendali yang digunakan ada PI-Adaptif. Kendali PI akan mengendalikan agar sistem memiliki respon yang cepat dan stabil. Kendali adaptif akan mengatasi parameter atau variabel sistem yang berubah berdasarkan waktu (time varying).
\end{abstract}

Kata kunci: turbocharger, PI-Adaptif, SI engine, turbo lag

\begin{abstract}
The majority of the passenger cars are designed to have reliable performance, fuel efficiency, and low exhaust emissions. In terms of the ability of a car able to overcome various existing road terrain, the reliable performance becomes the focus of the development of the cars today. Some ways to improve the performance of SI engines are variations in fuel selection, changing engine compression ratio, changing the value of air to fuel ratio (AFR), and using turbocharger. Turbocharger is one of the best ways. Turbocharger also has a weakness when applied in the SI engine that the occurrence of turbo lag conditions. This research designs the EAT control system to minimize turbo lag on the turbocharger. Method of control system used PI-Adaptif. PI control will control the system to have a fast and stable response. Adaptive control overcomes the parameters or system variables that change by time (time varying).
\end{abstract}

Keywords: turbocharger, PI-Adaptive, SI engine, turbo lag

\section{Pendahuluan}

Industri otomotif merupakan salah satu industri terbesar di Indonesia. Berdasarkan data dari Badan Pusat Statistik (BPS) Indonesia jumlah kendaraan bermotor terutama mobil berpenumpang mencapai 13.480 .973 buah pada tahun 2015 [1]. Mayoritas dari mobil-mobil berpenumpang tersebut didesain sehingga memiliki performa yang handal, hemat bahan bakar, dan rendah emisi gas buang. Dalam hal kemampuan sebuah mobil mampu mengatasi berbagai medan jalan yang ada maka performa yang handal menjadi fokus dari pengembangan mobil-mobil saat ini. Penelitian sebelumnya dilakukan untuk meningkatkan performa mesin bensin atau spark ignition engine (SI engine) untuk mampu mengatasi berbagai medan jalan yang ada. Beberapa cara untuk meningkatkan performa dari SI engine adalah variasi pemilihan bahan bakar[2], mengubah rasio kompresi mesin[3], mengubah nilai air to fuel ratio (AFR)[4], dan menggunakan turbocharger [5].
Berdasarkan cara-cara peningkatan perfoma SI engine, variasi nilai AFR dan menggunakan turbocharger merupakan cara yang termudah untuk diaplikasikan. Variasi pemilihan bahan bakar seperti pada Pai [2] memerlukan perbaikan infrastruktur terutama pada stasiun pengisian bahan bakar. Perubahan rasio kompresi yang dirancang oleh Thomas [3] memerlukan perubahan rancangan SI engine. Metode perubahan nilai AFR seperti pada Nugraha [4] mudah untuk diaplikasikan namun mengubah nilai AFR dari nilai stoikiometrinya akan berdampak emisi gas buang yang menyebabkan kendaraan tidak sesuai dengan strandar emisi gas buang yang telah ditetapkan.

Turbocharger atau supercharger memiliki kelebihan mampu memberikan peningkatan performa yang lebih signifikan daripada metode yang lain. Turbocharger juga memiliki kelemahan apabila diterapkan di SI engine yaitu terjadinya kondisi knocking dan turbo lag. Knocking 
terjadi ketika rasio kompresi yang berpengaruh pada suhu yang telah mencapai tingkat suhu yang tinggi sehingga bahan bakar yang seharusnya tidak terbakar, terbakar sebelum terdapat percikan api. Dalam hal ini pembakaran terlalu dini dan menyebabkan kerusakan kepala silinder dan piston. Knocking mudah terjadi pada SI engine daripada mesin diesel karena bahan bakar bensin memiliki flash point yang lebih rendah $\left(-45^{\circ} \mathrm{C}\right)$ daripada bahan bakar diesel yang memiliki flash point $\left(55^{\circ} \mathrm{C}\right)$ [6]. Turbocharger menghasilkan udara bertekanan, udara bertekanan akan menyebabkan peningkatan suhu yang berdampak pada mudah terbakarnya bahan bakar bensin. Knocking dapat diatasi dengan penambahan intercooler untuk menurunkan suhu tinggi keluaran dari turbocharger. Turbo lag yaitu waktu yang dibutuhkan oleh mesin untuk mencapai kecepatan yang dibutuhkan setelah pengemudi menekan pedal pegas [7]. Salah satu cara untuk meminimalkan turbo lag adala dengan electrically assisted turbocharger [8]. Electrically asissted turbocharger (EAT) adalah motor listrik yang berkerja apabila putaran mesin rendah maka EAT akan memberikan tambahan tekanan agar tekanan dorongan konstan, sehingga meningkatkan daya yang dihasilkan oleh mesin pada putaran mesin rendah.

Penelitian ini merancang sistem kendali yang pada EAT untuk meminimalkan turbo lag pada turbocharger. Metode sistem kendali yang digunakan ada PI-Adaptif. Kendali PI akan mengendalikan agar sistem memiliki respon yang cepat dan stabil. Kendali adaptif akan mengatasi parameter atau variabel sistem yang berubah berdasarkan waktu (time varying). Hasil dari sistem kendali akan diuji transient response, integral square error (ISE), dan tanggapan keadaan tunak (steady-state response) serta dibandingkan dengan sistem kendali PI konvensional.

\section{Metode}

\subsection{Turbocharger}

Turbocharger menggunakan energi gas buang panas dari mesin untuk menggerakan kompresor supercharging [9]. Prinsip kerja dari turbocharger adalah menggunakan gas buang untuk menggerakan turbin yang akan menggerakan kompresor supercharger. Kompresor dan turbin merupakan unit mandiri tanpa hubungan mekanis dengan mesin selain ducting untuk udara bertekanan dan gas buang. Rancangan mesin dengan turbocharger dapat dilihat pada Gambar 1.

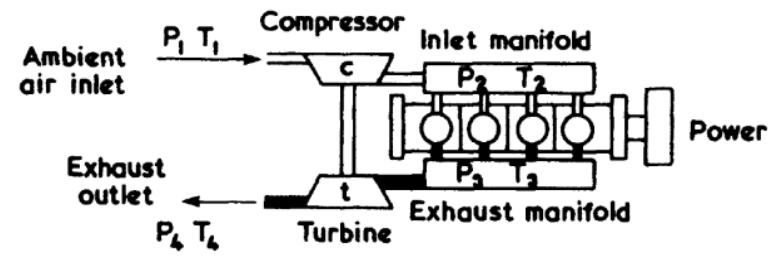

Gambar 1. Mesin dengan turbocharger

\subsubsection{Model tekanan turbocharger}

Tekanan turbin dan kompresor pada turbocharger dimodelkan berdasarkan persamaan gas ideal [10]. Tekanan dimodelkan berdasarkan perbedaan laju aliran massa yang masuk dan meninggalkan sistem. Model tekanan turbin dan kompresor ditunjukkan pada persamaan (1) dan persamaan (2).

$$
\begin{aligned}
& p_{t}=\frac{R \cdot T_{t}}{V_{t}} \int\left(\dot{m}_{t}-\dot{m}_{e m}\right) d t \\
& p_{c}=\frac{R \cdot T_{c}}{V_{c}} \int\left(\dot{m}_{a f}-\dot{m}_{c}\right) d t
\end{aligned}
$$

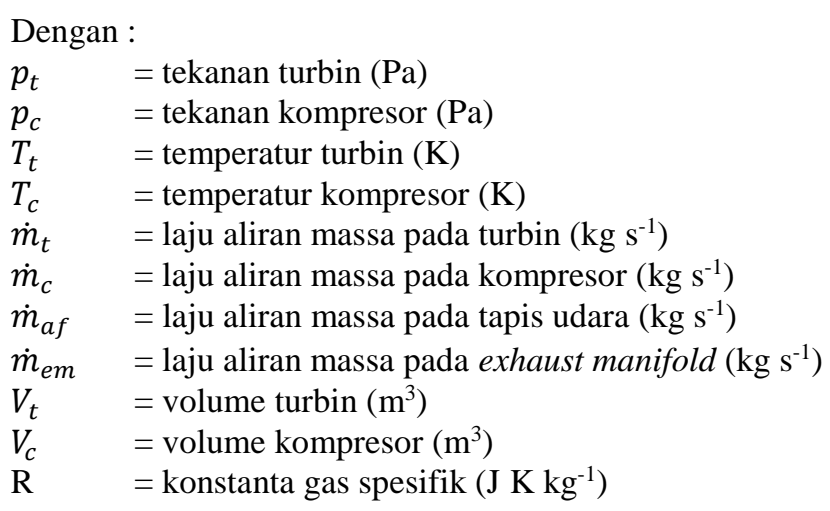

\subsubsection{Model laju aliran massa}

Model laju aliran massa turbin dan kompresor dimodelkan berdasarkan penelitian Wahlstrom [11]. Model Laju aliran massa turbin dan kompresor ditunjukkan pada persamaan (3) dan (4).

$$
\begin{aligned}
\dot{m}_{t} & =\frac{C_{d} A p_{e m} f_{\Pi t}}{\sqrt{R T_{e m}}} \\
\dot{m}_{c} & =\frac{p_{a f} \pi r_{c}^{3} \omega_{t c}}{R T_{a f}} \Phi_{c}
\end{aligned}
$$

Dengan :

$$
\begin{array}{ll}
A & =\text { Luas penampang turbin } \\
C_{d} & =\text { koefisien discharge } \\
f_{\Pi t} & =\text { fungsi rasio tekanan } \\
T_{e m} & =\text { Temperatur exhaust manifold }(\mathrm{K}) \\
\dot{m}_{t} & =\text { laju aliran massa pada turbin }\left(\mathrm{kg} \mathrm{s}^{-1}\right) \\
\dot{m}_{c} & =\text { laju aliran massa pada kompresor }\left(\mathrm{kg} \mathrm{s}^{-1}\right) \\
p_{a f} & =\text { tekanan tapis udara }(\mathrm{Pa}) \\
T_{a f} & =\text { temperatur tapis udara }(\mathrm{Pa}) \\
r_{c} & =\text { jari-jari kompresor }(\mathrm{m}) \\
\Phi_{c} & =\text { koefisien aliran volumetrik }(-)
\end{array}
$$

Model pada persamaan (3) dan persamaan (4) merupakan model turbocharger dengan variable geometry turbocharger. Pada penelitian ini, variable geometry 
turbocharger tidak digunakan untuk penyederhanaan model.

\subsection{Electrically Assisted Turbocharger (EAT)}

Skema plant SI engine dengan EAT ditunjukkan pada Gambar (2).

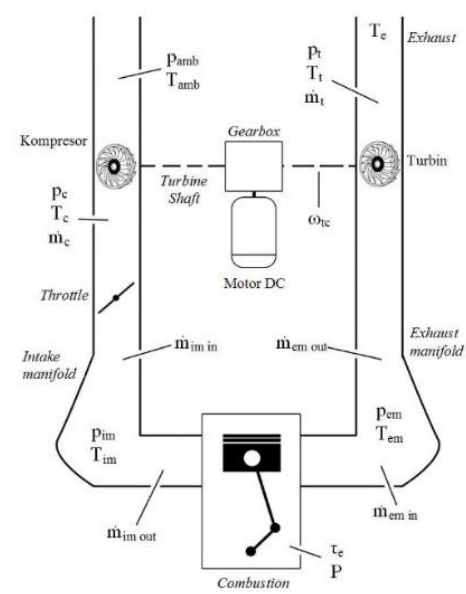

Gambar 2. Skema plant SI engine dengan EAT.

$p_{a m b}=$ tekanan ambient $(\mathrm{Pa})$

$p_{\text {im }}=$ tekanan intake manifold $(\mathrm{Pa})$

$p_{\text {em }} \quad=$ tekanan exhaust manifold $(\mathrm{Pa})$

$T_{i m} \quad=$ Temperatur intake manifold $(\mathrm{K})$

$T_{e m} \quad=$ Temperatur exhaust manifold $(\mathrm{K})$

$T_{e} \quad=$ Temperatur exhaust $(\mathrm{K})$

$\dot{m}_{\text {im in }}=$ laju aliran massa masuk ke intake manifold $(\mathrm{kg}$ $\mathrm{s}^{-1}$ )

$\dot{m}_{\text {im out }}=$ laju aliran massa keluar dari intake manifold $(\mathrm{kg}$ $\left.\mathrm{s}^{-1}\right)$

$\dot{m}_{\text {em in }}=$ laju aliran massa masuk ke exhaust manifold $(\mathrm{kg}$ $\mathrm{s}^{-1}$ )

$\dot{m}_{\text {em out }}=$ laju aliran massa keluar dari exhaust manifold $\left(\mathrm{kg} \mathrm{s}^{-1}\right)$

$\omega_{t c} \quad=$ kecepatan sudut turboshaft $\left(\mathrm{rad} \mathrm{s}^{-1}\right)$

$\tau_{e} \quad=$ torsi mesin $(\mathrm{Nm})$

$P \quad=$ daya mesin $($ watt $)$

Pada penelitian ini, sistem EAT yang dirancang tidak dilengkapi blow off valve dan waste gate untuk penyederhanaan model. Pada sistem yang dirancang, motor DC berperan sebagai aktuator tambahan dimana torsi motor menjadi torsi bantu untuk memutar turboshaft. Gearbox yang menghubungkan motor DC pada turboshaft dimodelkan sebagai summing point.

\subsection{Sistem Kontrol EAT}

2.3.1. Konversi Tekanan Kompresor ke Torsi Motor DC

Kontrol tekanan kompresor dilakukan dengan mengontrol torsi dari motor DC. Langkah ini dapat dilakukan dengan melakukan konversi dari galat tekanan kompresor menjadi torsi motor DC. Konversi dari galat tekanan kompresor menjadi torsi menggunakan faktor pengali atau gain. Sebelum nilai galat tekanan kompresor dikalikan dengan gain konversi, sebelumnya dilakukan saturation untuk membatasi nilai galat yang akan dikonversi. Saturation membatasi nilai galat dari tekanan kompresor yaitu dari 10.000 Pa sampai -10.000 Pa (batas galat yang yang dapat ditoleransi berdasarkan Watson pada[9]). Pembatasan dari saturation ini bertujuan untuk mempercepat respon sistem. Nilai gain didapatkan dari perbandingan nilai maksimal torsi dengan nilai maksimal galat tekanan kompresor di awal waktu $\left(\mathrm{t}_{0}\right)$. Nilai maksimal torsi yang akan dikontrol yaitu dari 1,5 $\mathrm{Nm}$ sampai $-1,5 \mathrm{Nm}$. Nilai negatif dari torsi diartikan sebagai torsi lawan. Nilai maksimal galat tekanan adalah $80.000 \mathrm{~Pa}$ sampai $-80.000 \mathrm{~Pa}$ (setpoint tekanan kompresor $180.000 \mathrm{~Pa}$ dan kondisi awal tekanan kompresor $100.000 \mathrm{~Pa}$ ), namun setelah melewati saturation menjadi $10.000 \mathrm{~Pa}$ sampai -10.000 Pa. Berdasarkan nilai maksimal torsi dan galat tekanan kompresor maka didapatkan nilai gain $1,5.10^{-4}$.

\subsubsection{Kontrol PI-Adaptif}

Penelitian ini menggunakan PI sebagai kontroler utama. Gain scheduling digunakan untuk merubah nilai parameter gain proporsional dan integral berdasarkan perubahan kondisi operasi. Perubahan kondisi didasarkan pada perubahan RPM pada mesin. Tabel 3.2 Menunjukkan penjadwalan parameter PI pada masing-masing kondisi.

Tabel 1. Penjadwalan nilai parameter PI

\begin{tabular}{ccc}
\hline Kondisi & $\mathrm{K}_{\mathrm{p}}$ & $\mathrm{K}_{\mathrm{I}}$ \\
\hline $2000 \mathrm{rpm}$ & 25.000 & 15 \\
$4000 \mathrm{rpm}$ & 30.000 & 10 \\
$6000 \mathrm{rpm}$ & 85.000 & 7 \\
\hline
\end{tabular}

Berdasarkan Tabel 1, nilai Kp dan KI akan menyesuaikan kondisi yang ada. Apabila nilai rpm mesin berada di antara dua kondisi maka akan menggunakan hubungan interpolasi linear. Interpolasi linear atau pendekatan akan membantu menentukan kondisi pada nilai rpm yang berada di antara dua kondisi. Nilai parameter gain proporsional dan integral diperoleh melalui metode trial and error dengan melihat respon keluaran dari system pada saat rising time, settling time, dan steady state.

\section{Hasil dan Analisa}

Pengujian pada penelitian ini dilakukan dalam tiga tahap yaitu pengujian tanpa gangguan, pengujian dengan gangguan positif, dan pengujian dengan gangguan negatif pada SI engine dengan ellectrically asissted turbocharger (EAT). Pengujian mengambil data respon keluaran dengan time sample 15 detik. Pengujian tanpa gangguan dilakukan untuk mengetahui respon transien sistem dan performa sistem secara umum dalam mengatasi turbo lag awal. 
Pengujian dengan gangguan positif dilakukan untuk mengetahui performa sistem untuk mengatasi turbo lag apabila sistem diberi gangguan positif berupa sudut bukaan throttle yang diperbesar seperti pada saat kendaraan berakselerasi.

Selain pengujian dengan variasi gangguan, pengujian akan dilakukan pada sistem EAT yang memiliki metode kontrol PI dan PI adaptif. Kedua metode kontrol akan diabndingkan untuk melihat efektivitas dari sistem adaptif apabila dibandingkan dengan metode kontrol PI konvensional. Variasi masukan kecepatan mesin dengan nilai $2.000 \mathrm{rpm}, 4.000 \mathrm{rpm}$, dan $6.000 \mathrm{rpm}$. Variasi kecepatan mesin dianggap konstan karena model SI engine yang digunakan tidak menggunakan sistem transmisi. Variasi masukan sudut bukaan throttle yaitu $15^{\circ}, 30^{\circ}, 45^{\circ}$, $60^{\circ}$, dan $90^{\circ}$.

Kontrol PI konvensional yang akan digunakan memiliki nilai parameter yaitu gain proporsional 120.000 dan integral 20. Nilai ini didapatkan dengan metode trial and error dengan melihat respon keluaran dari sistem pada saat rising time, settling time, dan steady state.

\subsection{Pengujian Tanpa Gangguan}

Pada pengujian ini dilakukan pada 3 variasi engine speed dengan 5 variasi sudut bukaan throttle pada tiap variasi engine speed. Variasi engine speed dilakukan dengan nilai engine speed $2.000 \mathrm{rpm}, 4.000 \mathrm{rpm}$, dan $6.000 \mathrm{rpm}$, sedangkan variasi bukaan throttle dilakukan pada $15^{\circ}, 30^{\circ}$, $45^{\circ}, 60^{\circ}$, dan $90^{\circ}$.

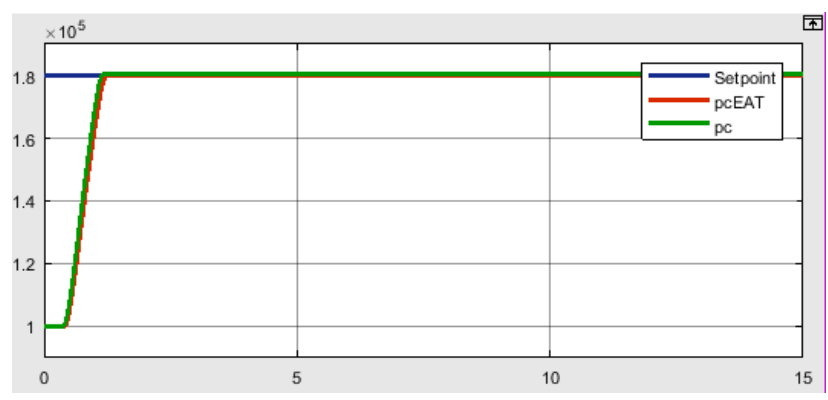

Gambar 3. Respon keluaran tekanan kompresor pada kecepatan mesin 2.000 rpm, sudut bukaan throttle $1^{\circ}$, dan tanpa gangguan

Berdasarkan Gambar 3 pc dan pcEAT mencapai setpoint 180.000 hampir bersamaan. Namun pc sedikit lebih cepat daripada pcEAT. Galat dari kedua sistem tidak jauh berbeda dan mendekati setpoint yang telah ditetapkan. Kedua metode kontrol memiliki performa yang baik dikarenakan turbo lag kurang dari 5 detik dan galat masih dalam batas yang ditoleransi yaitu $10.000 \mathrm{~Pa}$. Hasil pengujian variasi sudut bukaan throttle pada variasi lain ditunjukkan pada Tabel 2.
Tabel 2. Hasil pengujian tekanan kompresor tanpa gangguan

\begin{tabular}{lllll}
\hline $\begin{array}{l}\text { Sistem } \\
\text { Kontrol }\end{array}$ & $\begin{array}{c}\text { pc Keadaan } \\
\text { Tunak }(\mathrm{Pa})\end{array}$ & $\begin{array}{c}\text { Galat } \\
\text { Keadaan } \\
\text { Tunak }(\mathrm{Pa})\end{array}$ & $\begin{array}{c}\text { ISE } \\
\left(\mathrm{x} 10^{9}\right)\end{array}$ & $\begin{array}{c}\text { Settling time } \\
(\mathrm{s})\end{array}$ \\
\hline 2.000 & pcEAT & -76 & 5.469 & 1.46 \\
2.000 & pc & -370 & 5.187 & 1.4 \\
4.000 & pcEAT & 884 & 7.597 & 1.97 \\
4.000 & pc & 807 & 8.072 & 2.12 \\
6.000 & pcEAT & -67 & 8.907 & 2.34 \\
6.000 & pc & -429 & 9.512 & 2.74 \\
Rata-rata & pcEAT & 342.3 & 7.324 & 1.90 \\
Rata-rata & pc & 535.3 & 7.590 & 2.10 \\
\hline
\end{tabular}

Berdasarkan Tabel 2 didapatkan bahwa pcEAT memiliki nilai galat, ISE, dan settling time yang lebih kecil daripada pc. Hal ini menunjukkan bahwa performa PI-Adaptif lebih baik daripada PI dalam kondisi tanpa gangguan.

\subsection{Pengujian dengan Gangguan Positif}

Pada pengujian gangguan positif, sistem akan diberikan gangguan berupa sudut bukaan throttle yang diperbesar pada waktu tertentu. Gangguan ini akan menyebabkan tekanan kompresor akan turun. Pengujian akan melihat bagaimana respon keluaran sistem pada variasi kecepatan mesin, variasi sudut bukaan throttle, dan variasi gangguan. Variasi kecepatan akan dilakukan di $2.000 \mathrm{rpm}, 4.000 \mathrm{rpm}$, dan $6.000 \mathrm{rpm}$. Variasi sudut bukaan awal throttle pada $15^{\circ}, 30^{\circ}, 45^{\circ}$, dan $60^{\circ}$. Variasi gangguan yaitu $15^{\circ}, 20^{\circ}$, dan $25^{\circ}$.

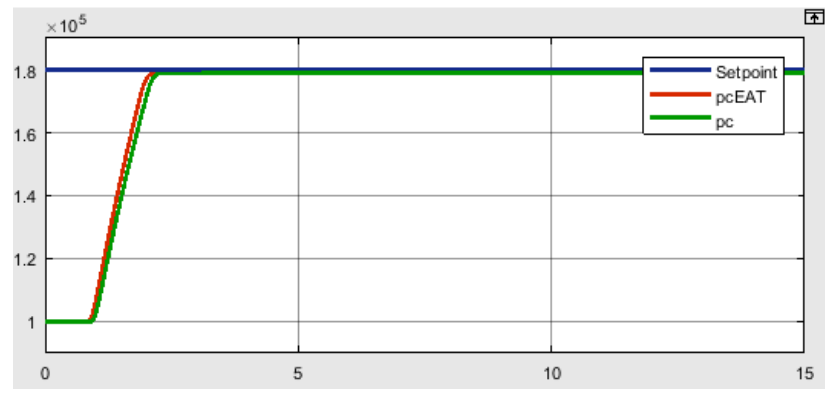

Gambar 4. Respon keluaran tekanan kompresor pada kecepatan mesin 4.000 rpm, sudut bukaan throttle $30^{\circ}$, dan gangguan positif $20^{\circ}$

Berdasarkan Gambar 4, kedua sistem mampu meredam atau mengkompensasi gangguan yang terjadi. Ketika terjadi gangguan positif (throttle terbuka lebih besar) saat akselerasi kendaraan, maka akan terjadi tekanan jatuh (pressure drop). Langkah untuk mengatasi hal ini adalah dengan mempercepat kecepatan turboshaft dengan meningkatkan torsi motor DC. Hasil pengujian variasi sudut bukaan throttle pada variasi lain ditunjukkan pada Tabel 3. 
Tabel 3. Hasil pengujian tekanan kompresor dengan gangguan positif

\begin{tabular}{llll}
\hline $\begin{array}{c}\text { Sistem } \\
\text { Kontrol }\end{array}$ & $\begin{array}{c}\text { pc Keadaan } \\
\text { Tunak }(\mathbf{P a})\end{array}$ & $\begin{array}{c}\text { Galat Keadaan } \\
\text { Tunak }(\mathbf{P a})\end{array}$ & ISE $\left(\mathbf{x} \mathbf{1 0}^{\mathbf{9}}\right)$ \\
\hline 2.000 & pCEAT & -80 & 5.388 \\
2.000 & pC & -378 & 2.108 \\
4.000 & pCEAT & 889 & 7.331 \\
4.000 & pC & 834 & 7.801 \\
6.000 & pcEAT & 92 & 8.464 \\
6.000 & pC & -203 & 9.058 \\
Rata-rata & pCEAT & -80 & 7.324 \\
Rata-rata & pC & 535.3 & 7.590 \\
\hline
\end{tabular}

Berdasarkan Tabel 3 didapatkan bahwa pcEAT maupun pc mampu menhadapi gangguan positif yang terjadi. Hal ini ditunjukkan pada nilai yang tidak jauh berbeda dengan pengujian tanpa gangguan. pcEAT memiliki nilai galat dan ISE yang lebih kecil daripada pc. Hal ini menunjukkan bahwa performa PI-Adaptif lebih baik daripada PI dalam kondisi tanpa gangguan.

\subsection{Pengujian dengan Gangguan Negatif}

Pada pengujian gangguan negatif, sistem akan diberikan gangguan berupa sudut bukaan throttle yang diperkecil pada waktu tertentu. Gangguan ini akan menyebabkan tekanan kompresor akan meningkat. Kondisi tekanan kompresor yang meningkat di luar rencana menyebabkan sistem tidak mampu mengkompensasi tambahan tekanan tersebut. Penambahan tekanan kompresor pada aplikasinya di lapangan biasa diantisipasi dengan blow off valve yang akan membuang kelebihan tekanan pada kompresor. Namun pada penelitian ini tidak menggunakan blow off valve karena fokus pada mengurangi turbo lag. Pengujian akan melihat bagaimana respon keluaran sistem pada variasi kecepatan mesin, variasi sudut bukaan throttle, dan variasi gangguan. Variasi kecepatan akan dilakukan di $2.000 \mathrm{rpm}, 4.000 \mathrm{rpm}$, dan $6.000 \mathrm{rpm}$. Variasi sudut bukaan awal throttle pada 450, 600, dan 900. Variasi gangguan yaitu $10^{\circ}, 20^{\circ}$, dan $25^{\circ}$.

Berdasarkan Gambar 5, kedua sistem terpengaruh sangat besar dengan gangguan negatif (sudut bukaan throttle diperkecil). Pada saat gangguan negatif terjadi tambahan tekanan. Tambahan tekanan yang berlebih di atas abtas yang dapat ditoleransi dapat merusak sistem. Hasil pengujian variasi sudut bukaan throttle pada variasi lain ditunjukkan pada Tabel 4.

Berdasarkan Tabel 4 keluaran tekanan kompresor dari kedua sistem terpengaruh dengan gangguan positif berupa bukaan throttle yang diperlebar. Hal ini dapat merusak sistem karena galat yang dihasilkan lebih dari batas aman yang dapat ditoleransi. Galat hampir dua kali dari setpoint yang ditetapkan. Selain itu ISE yang dihasilkan sangat besar, sehingga dapat dikatakan sistem tidak berjalan dengan baik.

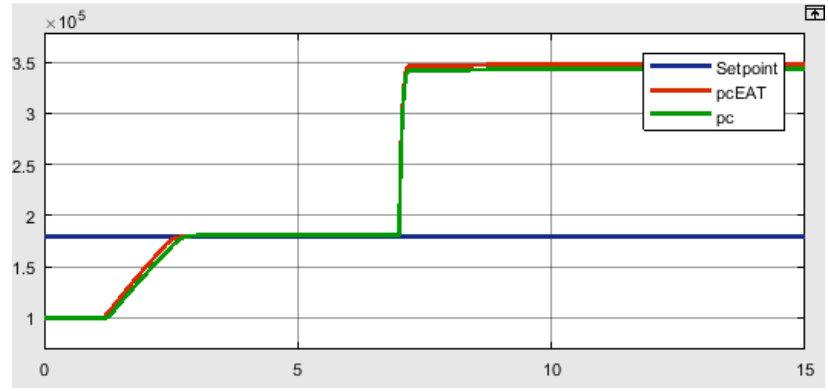

Gambar 5. Respon keluaran tekanan kompresor pada kecepatan mesin 6.000 rpm, sudut bukaan throttle $\mathbf{4 5}^{\circ}$, dan gangguan negatif $25^{\circ}$

Tabel 4. Hasil pengujian tekanan kompresor dengan gangguan negatif

\begin{tabular}{|c|c|c|c|}
\hline $\begin{array}{l}\text { Sistem } \\
\text { Kontrol }\end{array}$ & $\begin{array}{l}\text { pc Keadaan } \\
\text { Tunak }(\mathrm{Pa})\end{array}$ & $\begin{array}{l}\text { Galat Keadaan Tunak } \\
(\mathrm{Pa})\end{array}$ & ISE $\left(x 10^{9}\right)$ \\
\hline 2.000 & pcEAT & -77 & 5.768 \\
\hline 2.000 & $\mathrm{pc}$ & -335 & 5.487 \\
\hline 4.000 & pcEAT & -2657 & 8.785 \\
\hline 4.000 & $\mathrm{pc}$ & -2909 & 9.313 \\
\hline 6.000 & pcEAT & -63811 & 85.89 \\
\hline 6.000 & $\mathrm{pc}$ & -61045 & 80.89 \\
\hline Rata-rata & pcEAT & 22181 & 33.481 \\
\hline Rata-rata & $\mathrm{pc}$ & 21429 & 31.90 \\
\hline
\end{tabular}

\section{Kesimpulan}

Sistem EAT dengan PI-Adaptif dan PI mampu meminimalisir turbo lag dengan rata-rata nilai settling time 2 detik. Sistem dengan PI memiliki rata-rata galat tekanan kompresor $736 \mathrm{~Pa}$ lebih besar daripada PI Adaptif. Sistem EAT dengan PI-Adaptif dan PI mampu menjaga kestabilan tekanan kompresor pada saat terjadi gangguan positif. Sistem dengan PI Adaptif memiliki nilai ISE yang lebih daripada PI dengan nilai ISE 0.784 lebih kecil. Sistem EAT dengan PI-Adaptif dan PI mampu menjaga kestabilan tekanan kompresor pada saat terjadi gangguan negatif. Pada kecepatan mesin $2.000 \mathrm{rpm}$ dan $4.000 \mathrm{rpm}$ sistem dapat menggantikan fungsi dari blow off valve karena galat di bawah $10.000 \mathrm{~Pa}$. Pada kecepatan mesin $6.000 \mathrm{rpm}$ sistem sudah tidak mampu menggantikan blow off valve dan tekanan kompresor melebihi batas aman dengan galat berkisar $62.428 \mathrm{~Pa}$.

\section{Referensi}

[1] Badan Pusat Statistik, "Jumlah Kendaraan Bermotor," $2015 . \quad$ [Online]. Available: https://www.bps.go.id/linkTable Dinamis/view/id/1133. [Accessed: 13-May-2017].

[2] S. Pai, A. T. H. R, A. Rao, N. Shivaraju, and B. Sreeprakash, "Study of Impact of Ethanol Blends on SI Engine Performance and Emission," Natl. Conf. Challenges Res. Technol. Coming Decad. (CRT 2013), 2013. 
[3] R. Thomas, M. Sreesankaran, J. Jaidi, D. M. Paul, and P. Manjunath, "Experimental Evaluation of the Effect of Variable Compression Ratio on Performance and Emission of SI Engine Fuelled with Petrol and n-Butanol Blend at Different Loads," Perspect. Sci., 2016.

[4] S. I. Nugraha, M. Arsyahadij, M. A. Ridho, and A. Reynaldi, Muhammad Irsyad; Setiyono, Budi; Triwiyatrno, "LCGC Road Slope Based AFR Varying Control Using Hybrid PI-Fuzzy," 2016.

[5] J. R. Bumby and J. Spooner, E.S. ; Carter, J. ; Tennant, H. ; Mego, G.G. ; Dellora, G. ; Gstrein, W. ; Sutter, H. ; Wagner, "Electrical machines for use in electrically assisted turbochargers," IEE Int. Conf. Power Electron. Mach. Drives, vol. 2004, pp. v1-344-v1-344, 2004.

[6] M. H. Al-Abdullah, G. T. Kalghatgi, and H. Babiker, "Flash points and volatility characteristics of gasoline/diesel blends," Fuel, vol. 153, pp. 67-69, 2015.
[7] K. Rong, "Modeling of Turbocharged Spark Ignited Engine and Model Predictive Control of Hybrid Turbocharger," University of Florida, 2014.

[8] J. Rajeevan, M. H. Hans, A. Joseph, T. S. Kiran, and G. Kumaran, "Hybrid turbocharged SI engine with cooled exhaust gas recirculation for improved performance," Procedia Technol., vol. 24, pp. 444-451, 2016.

[9] M. S. Watson, N; Janota, Turbocharging: The Internal Combustion Engine, 1st ed. London: The Macmillan Press Ltd, 1982.

[10] F. Pettersson, "Simulation of a Turbo Charged Spark Ignited Engine," p. 76, 2000.

[11] J. Wahlstrom and L. Eriksson, "Modelling diesel engines with a variable-geometry turbocharger and exhaust gas recirculation by optimization of model parameters for capturing non-linear system dynamics," Proc. Inst. Mech. Eng. Part D J. Automob. Eng., vol. 225, no. 7, pp. 960-986, 2011. 